\title{
Resilient Behavior of Modified Asphalt Concrete Mixture
}

\author{
Saad Issa Sarsam*, Sara Ali Jasim \\ Department of Civil Engineering, College of Engineering, University of Baghdad, Baghdad, Iraq
}

Email address:

saadisasarsam@coeng.uobaghdad.edu.iq(S. I. Sarsam)

${ }^{*}$ Corresponding author

\section{To cite this article:}

Saad Issa Sarsam, Sara Ali Jasim. Resilient Behavior of Modified Asphalt Concrete Mixture. American Journal of Traffic and Transportation Engineering. Vol. 3, No. 2, 2018, pp. 18-23. doi: 10.11648/j.ajtte.20180302.11

Received: March 5, 2018; Accepted: April 10, 2018; Published: May 8, 2018

\begin{abstract}
Asphalt concrete pavement is designed to exhibit elastic behavior under loading at cold weather condition and a combination of elastic, plastic and viscous behavior at hot weather condition. Distress of the pavement usually starts with initiation of micro cracking due to load repetition, while such cracks can heal by themselves in slow process under repeated loading, external or internal heating, and provision of rest period at ambient temperature. The aim of this work was to assess the resilient behavior of modified asphalt concrete using three types of polymer additives such as starien- butadien- stairen (SBS), low density poluetheline (LDPE), and scrap tire rubber. Beam specimens of $381.0 \mathrm{~mm}$ length, $76.2 \mathrm{~mm}$ width, and $76.2 \mathrm{~mm}$ thickness have been prepared with optimum asphalt content requirement and with extra $0.5 \%$ asphalt above and below the optimum. Beam specimens were tested under repeated flexure stress. The applied stress level was $138 \mathrm{kPa}$ at $25^{\circ} \mathrm{C}$. The loading cycle consist of 0.1 second loading application followed by 0.9 seconds of rest period. The test was conducted for 660 load repetitions using the Pneumatic repeated load system (RPLS) to allow for the initiation of micro cracks. After the specified loading cycles, the test was stopped and the Specimens have been withdrawn from the testing chamber of PRLS and stored in the oven for two hours at $60^{\circ} \mathrm{C}$ environment to allow for possible micro crack healing. The specimens were then subjected to another loading cycle. Permanent, total and resilient deformations were captured through LVDT. The resilient modulus was calculated and compared among various conditions. Test results showed that the implemented polymer additives and the process of micro crack healing have positive influence on resilient modulus and deformation variables of asphalt concrete.
\end{abstract}

Keywords: Asphalt Concrete, Polymer Additives, Resilient Modulus, Repeated load, Microstrain

\section{Introduction}

Asphalt cement mixture is a visco-elastic material where the rate of load application and temperature have a great influence on its behavior. The quality of asphalt concrete pavement can be assessed by its resilient characteristics (ability to retain its original shape after releasing the load). Using of polymer additives in pavement construction is known to give the conventional asphalt concrete better engineering properties as well as durable asphalt concrete pavement. The resilient characteristics of asphalt concrete mixture such as resilient deformation and resilient modulus which can be described as the ratio of applied deviator stress to recoverable or resilient strain are considered as essential parameters in the design of the flexible pavement. Resilient characteristics are a measure of materials responses to load and deformation, [1]. Generally, higher resilient modulus indicates greater resistance to deformation, while the higher resilient deformation indicates more flexibility of the pavement. Resilient modulus can be determined at moderate temperature of $25^{\circ} \mathrm{C}$ and stress level of (138Kpa), [2]. Additives and modifiers such as liquid anti-strip (LAS), styrene butadiene styrene (SBS), poly phosphoric acid (PPA), and hydrated lime have been investigated by [3] to evaluate the influence of polymer modified bitumen in pavements. The use of polymer modified binder can significantly decrease rutting in asphalt concrete mixture. An increase in pavement lifetime can be expected if using polymer modified bitumen on low-volume roads with a considerable amount of heavy traffic, [4]. Increasing the stiffness of the bitumen is also likely to increase the dynamic stiffness of the asphalt. This will improve the load spreading capability of the material, increase the structural strength and lengthen the expected service life of the pavement. Alternatively, it may 
be possible to achieve the same structural strength but with a thinner layer, [5]. In a study done by [6], laboratory tests were conducted to evaluate the long-term field performance of pavements with polymer modified bitumen PMB compared to neat bitumen. Field samples were taken from asphalt concrete pavements with and without PMB, while laboratory samples of asphalt concrete with neat and $\mathrm{PMB}$ were prepared. These samples were then tested at $50^{\circ} \mathrm{C}$ in a wheel tracking device. The results of the study indicated that use of polymer modified binders improves the deformation resistance of asphalt mixes, compared with asphalt mixes containing ordinary bitumen. Cycle dynamic deflection is the asphalt concrete test profile most closely simulating the real conditions of material behaviour under traffic load effect on a bituminous surface, [7]. In order to improve its engineering properties, asphalt is frequently modified by various polymers. The most successful polymer modifiers are thermoplastic elastomers, especially the styrene-butadiene-styrene (SBS), [8]. The most common plastomers asphalt modifiers are polyethylene and polypropylene. From the observations obtained in [9] study, one should not disqualify binders modified by reactive ethylene ter-polymers RET and Poly-phosphoric acid PPA from the performance competition at higher temperatures. It was shown that these materials are stiff enough at low temperatures and may show less deformation after longer aging. The implication of polymers into the asphalt cement structure had proved to increase the viscosity, and reduce the thermal sensitivity of the binder, the resistance to permanent deformation and fatigue were also increased, [10-13]. The aim of this work is to assess the resilient behavior of asphalt concrete modified with polymer additives (SBS, LDPE, and rubber) under repeated flexure stresses.

\section{Materials and Methods}

\subsection{Asphalt Cement}

Penetration grade of 44 Asphalt cement obtained from Daura Refinery, has been implemented in this investigation. Table 1 present the physical properties of the asphalt cement.

Table 1. Physical properties of asphalt cement.

\begin{tabular}{llll}
\hline Property of asphalt cement as per ASTM. [11] & Result & Unit & SCRB Specification [12] \\
\hline Penetration $\left(25^{\circ} \mathrm{C}, 100 \mathrm{~g}, 5 \mathrm{sec}\right)$ ASTM D5-97 & 44 & $1 / 10 \mathrm{~mm}$ & $40-50$ \\
Softening Point (Ring \& Ball) ASTM D5-36 & 48.9 & ${ }^{\circ} \mathrm{C}$ & $50-60$ \\
Ductility $\left(25^{\circ} \mathrm{C}, 5 \mathrm{~cm} / \mathrm{min}\right)$ ASTM D113-07 & 120 & $\mathrm{~cm}$ & $>100$ \\
Kinematic viscosity at $135^{\circ} \mathrm{C}$ ASTM D-2170 & 365 & $\mathrm{C}$. St & $(1.01-1.05)$ \\
Specific gravity at $25^{\circ} \mathrm{C}$ ASTM D-70 & 1.04 & & $>55 \%$ \\
After Thin-Film Oven test as per ASTM D1754 & & $\%$ & $>25$ \\
Retained penetration of original, $\%$ D946 & 60 & $\mathrm{~cm}$ & $<0.75$ \\
Ductility at $25^{\circ} \mathrm{C}, 5 \mathrm{~cm} / \mathrm{min}$ & 75 & $\%$ & \\
Loss in weight $\left(163^{\circ} \mathrm{C}, 50 \mathrm{~g}, 5 \mathrm{~h}\right)$ ASTM D1754 & 0.34 & & \\
\hline
\end{tabular}

\subsection{Coarse and Fine Aggregates}

Crushed coarse aggregate was obtained from Al-Nibaee quarry and implemented in this work. It consists of hard, strong, and durable pieces. The gradation of coarse aggregate was typical for binder course construction with a maximum size of $19.0 \mathrm{~mm}$ ranges and retained on $(4.75 \mathrm{~mm})$ sieve according to SCRB R/9, [12] specification. Fine aggregate was also obtained from Al-Nibaee quarry. The fine aggregates gradation was passing $4.75 \mathrm{~mm}$ and retains on $0.075 \mathrm{~mm}$. It consists of tough grains, free from clay, loam or other deleterious substance. The physical properties of coarse and fine aggregate are shown in Table 2.

Table 2. Physical properties of Al-nibaee coarse and fine aggregates.

\begin{tabular}{lll}
\hline Property as per ASTM, [11] & Coarse Aggregate & Fine Aggregate \\
\hline Bulk Specific Gravity (ASTM C127 and C128) & 2.680 & 2.630 \\
Percent Water Absorption (ASTM C127 and C128) & 0.423 & 0.542 \\
Percent Wear (Los-Angeles Abrasion) (ASTM C131) & 21.7 & \\
\hline
\end{tabular}

\subsection{Mineral Filler}

Portland cement has been implemented as filler material. It was thoroughly dry and free from lumps or aggregations of fine particles. The physical properties are illustrated in Table 3.

Table 3. Physical properties of portland cement.

\begin{tabular}{ll}
\hline Physical Properties & \\
\hline$\%$ Passing Sieve No.200 $(0.075 \mathrm{~mm})$ & 98 \\
Specific Surface Area $\left(\mathrm{m}^{2} / \mathrm{kg}\right)$ & 3.55 \\
\hline
\end{tabular}

\subsection{Polymer Additives for Asphalt Cement}

Three types of polymer additives have been implemented in this work; Styrene-butadiene-styrene (SBS), Low density polyethylene (LDPE), and Scrap Tire rubber. The three types of modified asphalt cement binders were manufactured at laboratory. Details of the production process and the properties were published elsewhere, [13]. Figure 1 shows the polymer additives implemented. 

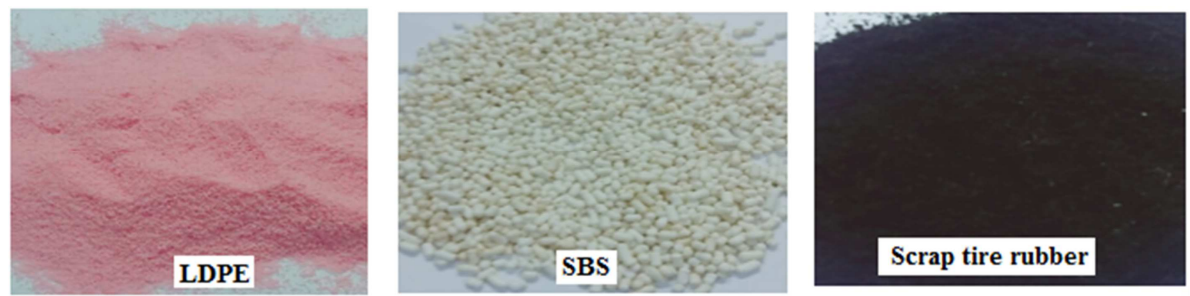

Figure 1. Polymer Additives Implemented in the Study.

\subsection{Selection of Binder Course Overall Aggregate Gradation}

The overall dense gradations that was selected in this study follow SCRB R/9, [12] specification for Hot-mix asphalt paving mixtures usually used for binder course with aggregate maximum size of $(19 \mathrm{~mm})$. Figure 2 . Show the gradation for binder layer.

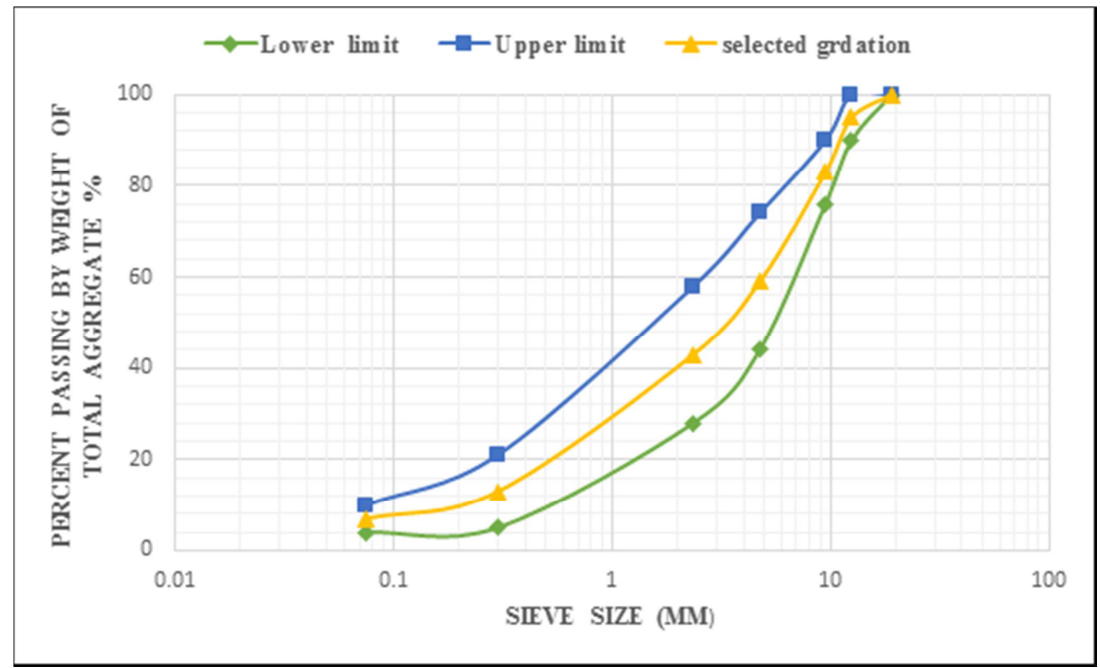

Figure 2. Selected gradation of aggregate for binder course, scrb, [10].

\subsection{Preparation of Modified Asphalt Concrete Beam Specimens}

The aggregate mixture of the binder course as per SCRB, [10] was heated to $150^{\circ} \mathrm{C}$, while the pure or modified asphalt cement were heated to $160^{\circ} \mathrm{C}$, then added to the aggregates and mixed thoroughly for three minutes using mechanical mixer until asphalt had sufficiently coated the surface of the aggregates and a homogeneous mixture is achieved. The beam mold of $381.0 \mathrm{~mm}$ length, $76.2 \mathrm{~mm}$ width, and $76.2 \mathrm{~mm}$ height was heated to $150^{\circ} \mathrm{C}$. The internal surface of the mold was oiled slightly using mineral oil and a sheet of aluminum foil was placed on the base of mold to prevent sticking, The hot asphalt concrete mixture was transferred to heated mold, laid and spread uniformly with a heated spatula then subjected to static compaction of $30 \mathrm{kN}$ applied through steel plated of 80 $\mathrm{mm}$ thickness. The applied pressure was maintained for three minutes at $150^{\circ} \mathrm{C}$ to achieve the target Specimen's bulk density and thickness. The mold was left for 24 hours to cool at room temperature and then the beam specimens were extruded from the mold. Figure 3. exhibit the compaction process of the mold, while Figure 4 shows the casting mold. Figure 5 present part of the prepared beam specimens. Beams have been prepared with optimum asphalt content requirement and with extra $0.5 \%$ asphalt above and below the optimum.

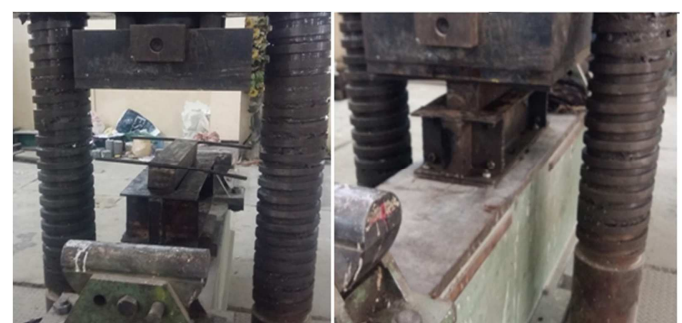

Figure.3. Compaction process of the mold.

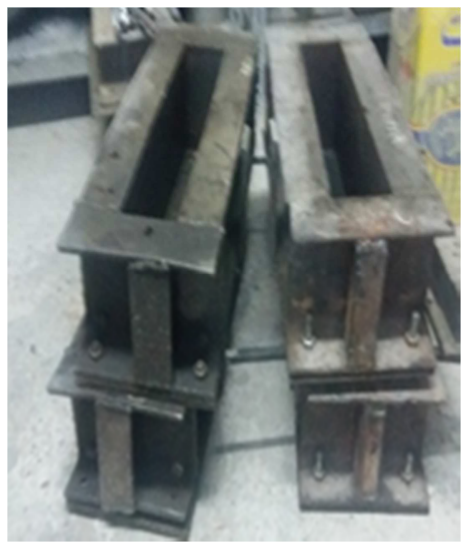

Figure 4. The casting molds. 


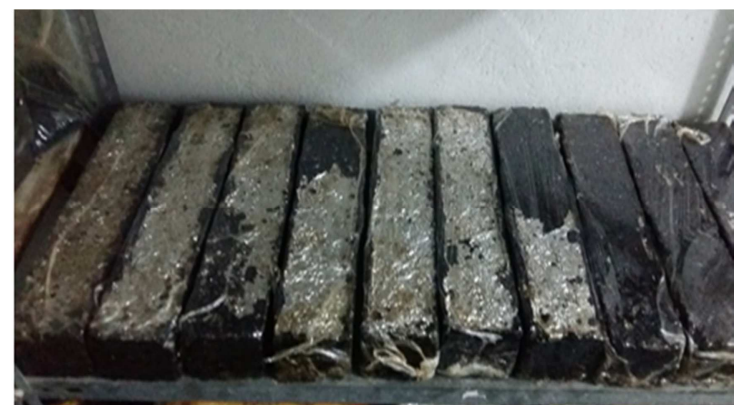

Figure 5. Part of the prepared beam specimens.

\subsection{Testing Beam Specimens for Repeated Flexural Bending}

The repeated flexural bending test was conducted in the Laboratory using pneumatic repeated Load system apparatus (PRLS). The system apparatus has comprehensive testing capabilities that permit fatigue and stiffness (resilient modulus) testing. Four-point loading test with free rotation beam holding fixture at all loading and reaction point is usually used to estimate cracking potential in the flexural beam fatigue test. The numbers of cycles (fatigue life) that cause failure of the beam is commonly considered as indicator of fatigue cracking potential. The specimen is left in the system chamber for one hour at testing temperature $\left(25^{\circ} \mathrm{C}\right)$ to allow for uniform distribution of temperature within the specimen and its position of applied loading is checked exactly. LVDT (Linearly Variable Differential Transformer) which convert the mechanical signal (displacement) to electrical signal has been used to get test results. Position of the LVDT onto the specimen was fixed such that the LVDT displacement reading is close to zero. Beam specimens were tested under repeated flexure stress using the PRLS. The stress level was $138 \mathrm{kPa}$ at $25^{\circ} \mathrm{C}$ environment. The loading cycle consist of 0.1 second loading application followed by 0.9 seconds of rest period. The test was conducted for 660 load repetitions using the Pneumatic repeated load system (RPLS) to allow for the possible initiation of micro cracks. After the specified loading cycles, the test was stopped and the Specimens have been withdrawn from the testing chamber of PRLS and stored in the oven for two hours at $60^{\circ} \mathrm{C}$ environment to allow for possible micro crack healing. The specimens were then subjected to another loading cycle. Details of the asphalt content determination and target density can be found in [14].

\subsection{Crack Healing Cycle Technique Adopted}

The possible micro crack healing technique implemented in this work was by the external heating process. After the initiation of micro cracks after 660 of flexure load repetitions, the test was stopped. Specimens were withdrawn from the testing chamber of PRLS as mentioned before, and stored in an oven for two hours at $60^{\circ} \mathrm{C}$ to allow for micro crack healing. Specimens were subjected to another cycle of repeated flexure stress at $25^{\circ} \mathrm{C}$ for another 660 repetitions. The testing Temperate was $\left(25^{\circ} \mathrm{C}\right)$, while the applied stress was (138) $\mathrm{kPa}$. Figure 6 demonstrates testing setup of the beams.

\subsection{Analysis of Deformation Under Repeated Flexural Bending}

The determination of the resilient and permanent deformations have been conducted at the following load repetitions: $(1,10,50,100,200,300,400,500$, and 660). The permanent strain $(\varepsilon p)$ was calculated by applying equation (1):

$$
\varepsilon \mathrm{p}=\frac{p d^{*} 10^{6}}{h}
$$

Where:

$\varepsilon_{\mathbf{p}}$ : Permanent microstrain $(\mathrm{mm} / \mathrm{mm})$.

$p d$ : Reading of dial gauge for permanent strain

$h$ : specimen diameter $(\mathrm{mm})$.

The resilient deformation determined at the load repetition of (50) to (100). The resilient strain $\left(\varepsilon_{\mathrm{r}}\right)$ and resilient modulus (Mr) were calculated as follows using equations 2 and 3:

$$
\varepsilon_{\mathrm{r}}=\frac{r d}{h}
$$

Where:

$\varepsilon_{\mathrm{r}}$ : Vertical resilient strain $(\mathrm{mm} / \mathrm{mm})$.

$r d$ : Reading of dial gauge for vertical resilient strain $h$ : specimen diameter ( $\mathrm{mm})$.

$$
\mathrm{Mr}=\frac{\sigma}{\varepsilon_{r}}
$$

Where:

Mr: Resilient modulus $\left(\mathrm{N} / \mathrm{mm}^{2}\right)$.

$\sigma$ : Repeated diametral stress $\left(\mathrm{N} / \mathrm{mm}^{2}\right)$.

$\varepsilon_{\mathrm{r}}$ : Vertical resilient strain $(\mathrm{mm} / \mathrm{mm})$.

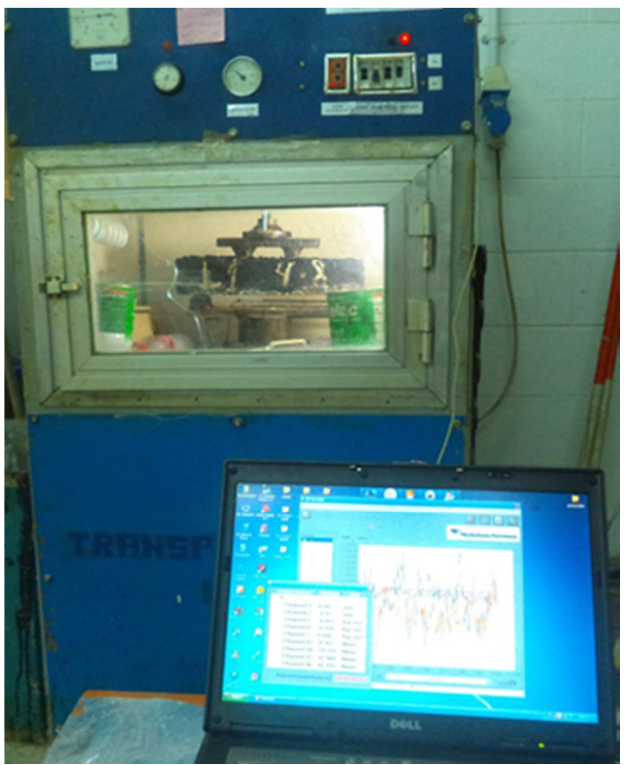




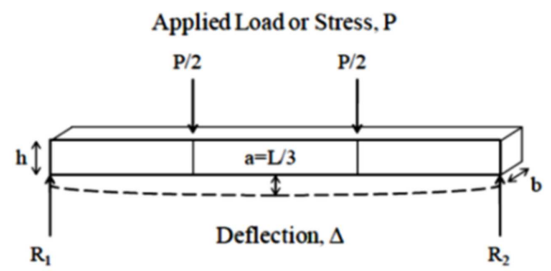

Figure 6. Testing setup of beam specimen.

\section{Results and Discussion}

\subsection{Impact of Healing Cycle and Polymer Additives on Resilient Strain}

Figure 7 shows the impact of healing cycle and polymer additives on resilient microstrain for asphalt concrete beam specimens. The behavior of resilient strain varies according to the percentage of asphalt and type of additive, and decreases with healing as compared to those before crack healing process.

At $4.3 \%$ asphalt content, the resilient strain decreases by $39 \%$ after healing cycle as compared with control mix. For mixture with optimum asphalt content of $4.8 \%$, the resilient strain decreases $22 \%$ after healing cycle as compared with control mix. While, at 5.3\% asphalt content, the reduction in resilient strain was $29 \%$ after healing cycle as compared with control mix. When polymer additives were implemented, similar Behavior could be detected. For LDPE modified asphalt mixture at $(4.8,5.3$, and 5.8$) \%$ asphalt content, the resilient strain decreases by $(6,69$, and 72$) \%$ after the healing cycle as compared with control mix. For SBS modified asphalt mixture at $(5.1,5.6$, and 6.1$) \%$ asphalt content, the resilient strain decreases by $(11,7$, and zero $) \%$ after the healing cycle as compared with control mix. For scrap tire rubber modified asphalt mixture at $(4.8,5.3$, and 5.8)\% asphalt content, the resilient strain decreases by $(25,30$, and $60) \%$ after the healing cycle as compared with control mix.

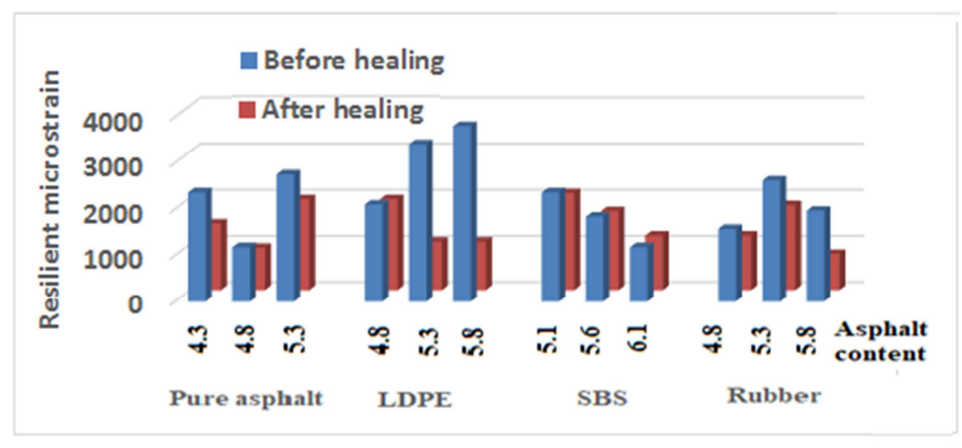

Figure 7. Influence of crack healing and polymer additives on resilient microstrain.

\subsection{Impact of Polymer Additives and Crack Healing on Resilient Modulus}

Resilient modulus was described as the ratio of applied deviator stress to recoverable or resilient strain. Resilient modulus is a measure of materials responses to load and deformation. Generally, higher modulus indicates greater resistance to deformation. Figure 8 . Shows the impact of implementing crack healing and polymer additives on resilient modulus of asphalt concrete, the resilient modulus generally increases after the healing cycle. For pure asphalt mixture at $(4.3,4.8$ and 5.3$) \%$ asphalt content, it can be noticed that the resilient modulus increases by $(64,29,40) \%$ respectively after the healing cycle as compared to mixture before healing cycle. For LDPE modified mixture at (4.8, 5.3 and 5.8)\% asphalt content, the resilient modulus increases by $(8,228,264) \%$ respectively after the healing cycle as compared to mixture before healing cycle. For SBS modified mixture at (5.1, 5.6 and 6.1$) \%$ asphalt content, the resilient modulus increases by $(12,7,0) \%$ respectively after the healing cycle as compared to mixture before healing cycle. For Rubber modified mixture at $(4.8,5.3$, and 5.8)\% asphalt content, the resilient modulus increases after the healing cycle by $(33,44,150) \%$ respectively as compared with mixture before healing cycle. The impact of asphalt content on resilient modulus was not significant for SBS mixtures while it was variable for other additives as demonstrated in Figure 8 .

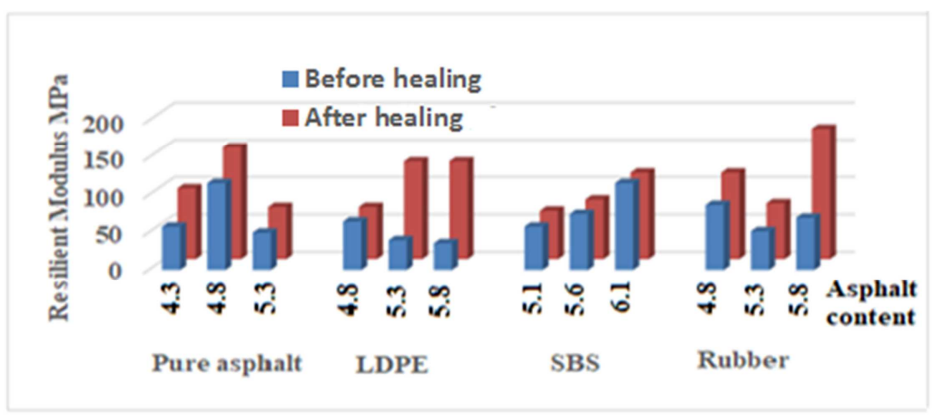

Figure 8. Influence of crack healing and polymer additives on resilient modulus. 


\section{Conclusions}

Based on the testing program, the following conclusion can be drawn.

(1)- For LDPE modified asphalt mixture at (4.8, 5.3, and 5.8$) \%$ asphalt content, the resilient strain decreases by $(6,69$, and 72$) \%$ after the healing cycle as compared with control mix. For SBS modified asphalt mixture at (5.1, 5.6, and 6.1$) \%$ asphalt content, the resilient strain decreases by $(11,7$, and zero $) \%$ after the healing cycle as compared with control mix. For scrap tire rubber modified asphalt mixture at (4.8, 5.3, and 5.8)\% asphalt content, the resilient strain decreases by $(25,30$, and 60$) \%$ after the healing cycle as compared with control mix.

(2)- The resilient modulus at optimum asphalt content increases by (29), (7), (44), (228)\% for pure asphalt, SBS, Rubber, and LDPE modified mixes after healing cycle respectively as compared with control mix after crack healing cycle.

(3)- The modified asphalt concrete exhibit little susceptibility to the change in asphalt content from resilient microstrain and modulus points of view for SBS modified asphalt mixtures, while the variations was significant for LDPE modified asphalt mixtures.

\section{References}

[1] S. I. Sarsam "Evaluation of changes in structural properties of Asphalt Concrete by the addition of scrap tire rubber". Proceeding -2ND Jordan Scientific conference of civil Engineering 16-17 November -Jordan. 1999.

[2] S. I. Sarsam, and A. AL-Lamy "Fatigue Life Assessment of Modified Asphalt Concrete", International Journal of Scientific Research in Knowledge, 3(2), pp. 030-041. 2015.

[3] P. Pay "Effect of polymer modified bitumen on deformation characteristics of low-traffic asphalt pavements". MSc. Thesis, Norwegian University of science and technology, NTNY, department of civil and environmental engineering, 2017.
[4] Liu, Hanbing, et al. "Short-Term Aging Effect on Properties of Sustainable Pavement Asphalts Modified by Waste Rubber and Diatomite". Sustainability 9.6 pp.996. 2017.

[5] C. Rodrigues, and R. Hanumanthgaru, " Polymer modified bitumen and other modified binders". In R. N. Hunter, A. Self, \& J. Read. The Shell Bitumen Handbook pp. 150- 76. London: ICE Publishing, 2015.

[6] B. O. Lerfald, and J. Aurstad, "Use of Polymer Modified Binders to develop more Lasting Pavements". 11th International Conference on Asphalt Pavements, Nagoya: International Society for Asphalt Pavements (ISAP). 2011.

[7] A. V. Rudensky, "Road concrete pavement on modified bitumen". Voronezh State University of Arch. And Civil Eng. Voronezh. pp.143. 2007.

[8] R. Hampl, O. Vacin, M. Jasso, J. Stastna, L. Zanzotto "Modelling of Tensile Creep and Recovery of Polymer Modified Asphalt Binders at Low Temperatures. Applied rheology, 25, pp.1-8. 2015.

[9] S. Sarsam and S. Al-Sadik "Contribution of Crumb Rubber in the Aging Process of Asphalt Concrete. International Journal of Scientific Research in Knowledge, (IJSRK) 2(9), pp. 404415. 2009.

[10] I. Kalgin, Yu, A. Strokin, and E. Tyukov, "Advanced technologies of road pavement construction and rehabilitation with application of modified bitumen. Voronezh regional publish house. pp. 224. 2014.

[11] American Society for Testing and Materials, "Annual Book of ASTM Standards, Road and Paving Materials; VehiclePavement System, Vol. 04.03. 2013.

[12] SCRB. General Specification for Roads and Bridges, "Section R/9, Hot-Mix Asphalt Concrete Pavement", Revised Edition. State Corporation of Roads and Bridges, Ministry of Housing and Construction, Republic of Iraq. 2003.

[13] S. Sarsam and S. Jasim "Assessing the properties of modified asphalt cement prepared under controlled heat and pressure". Proceedings, Scientific conference of Ministry of construction, housing, municipality and public work, October 8-9, 2017, Baghdad.

[14] S. Sarsam, and H. Husain "Impact of Repeated Load on Crack Healing Cycles of Asphalt Concrete". American Journal of Traffic and Transportation Engineering 1.3 pp. 26-33. 2016. 